\title{
The effects of indoor and outdoor air pollution on the prevalence of adults' respiratory diseases in four Chinese cities: a comparison between 2017-2018 and 1993-1996
}

\author{
Meilin Yan ${ }^{1}$, Jicheng Gong ${ }^{1}$, Qin Liu ${ }^{2}$, Wenyan $\mathrm{Li}^{2}$, Xiaoli Duan ${ }^{3}$, Suzhen $\mathrm{Cao}^{3}, \mathrm{Sai}^{3}$, Lingyan $\mathrm{He}^{4}$, \\ Zixuan Yin ${ }^{4}$, Weiwei Lin ${ }^{5}$ Junfeng Jim Zhang ${ }^{6,7,8}$
}

${ }^{1}$ Beijing Innovation Center for Engineering Science and Advanced Technology, State Key Joint Laboratory for Environmental Simulation and Pollution Control, College of Environmental Sciences and Engineering, And Center for Environment and Health, Peking University, Beijing, China; ${ }^{2}$ School of Public Health and Management, Research Center for Medicine and Social Development, Collaborative Innovation Center of Social Risks Governance in Health, Chongqing Medical University, Chongqing, China; ${ }^{3}$ School of Energy and Environmental Engineering, University of Science and Technology Beijing, Beijing, China; ${ }^{4}$ Key Laboratory for Urban Habitat Environmental Science and Technology, School of Environment and Energy, Peking University Shenzhen Graduate School, Shenzhen, China; ${ }^{5}$ Department of Occupational and Environmental Health, School of Public Health, Sun Yat-Sen University, Guangzhou, China; ${ }^{6}$ Global Health Research Center, Duke Kunshan University, Kunshan, China; ${ }^{7}$ Nicholas School of the Environment and Duke Global Health Institute, Duke University, Durham, USA; ${ }^{8}$ Guangzhou Institute of Respiratory Health, The First Affiliated Hospital of Guangzhou Medical University, Guangzhou, China

Contributions: (I) Conception and design: J Gong, M Yan, JJ Zhang; (II) Administrative support: J Gong; (III) Provision of study materials: J Gong, J Zhang; (IV) Collection and assembly of data: Q Liu, W Li, X Duan, S Cao, S Li, L He, Z Yin, W Lin; (V) Data analysis and interpretation: M Yan, J Gong; (VI) Manuscript writing: All authors; (VII) Final approval of manuscript: All authors.

Correspondence to: Jicheng Gong, PhD. College of Environmental Sciences and Engineering, Peking University, 5 Yiheyuan Road, Haidian 100871, Beijing, China. Email: jicheng.gong@pku.edu.cn.

Background: Over the past decades, both ambient and household air pollution have changed in several aspects, including the emission sources and the concentrations of pollutants, in many Chinese cities. It is unknown whether these changes are associated with changes in health conditions, especially given changes in other factors due to rapid economic growth.

Methods: Two cross-sectional surveys were conducted in two periods spanning more than twenty years (1993-1996 vs. 2017-2018) in four Chinese cities of Chongqing, Wuhan, Lanzhou, and Guangzhou. Data were collected regarding adults' respiratory disease, smoking status, education, occupation, and household characteristics. Ambient air pollution data were obtained for each study. We first used logistic regression models to construct the district-specific adjusted disease prevalences. In the second stage, first-difference regression models were employed to examine whether the change in respiratory diseases prevalences was associated with the change in outdoor air pollution and indoor air pollution surrogates.

Results: A total of 7,557 and 9,974 households were participating in Period 1 (1993-1996) and Period 2 (2017-2018), respectively. Compared to Period 1, we found substantial reductions in the ambient air pollution concentrations, and a suggestive improvement in cooking-related indoor air pollution in Period 2. We observed decreases in the district-specific covariate-adjusted prevalences of both asthma and chronic bronchitis among participants, with an average reduction of $3.6 \%$ (range: $0.0 \%$ to $24.3 \%$ ). From Period 1 to Period 2, one percent decrease in the proportion of cooking with coal was associated with a $19.0 \%(95 \%$ CI, 0.96-37.04\%) decrease in the prevalence of males' chronic bronchitis and a 1.86\% (0.69-3.04\%) increase in the prevalence of females' asthma. Little evidence was observed regarding the potential health benefits associated with the decreases in ambient air pollution levels.

Conclusions: The substantial reduction in household use of coal for cooking might be an important contributor to the decrease in adults' respiratory disease prevalence from 1993-1996 to 2017-2019 in four 
Chinese cities. Changes in this indoor air pollution source, along with other risk factors for respiratory diseases, may have masked respiratory health benefits associated with reductions in outdoor air pollution levels.

Keywords: Air pollution; asthma; bronchitis

Submitted Jun 03, 2020. Accepted for publication Apr 25, 2021.

doi: $10.21037 /$ jtd-20-2121

View this article at: https://dx.doi.org/10.21037/jtd-20-2121

\section{Introduction}

Notable temporal trends in the prevalences of humans' respiratory diseases have been documented for several western countries $(1,2)$. Since the 1990s, while the prevalence of asthma remains increasing among children and young adults in some countries, it is relatively stable or slightly decreasing in others (1). In China, limited data is available concerning the change in respiratory disease prevalence over time, with some studies for few areas (3-7). For example, a study showed that asthma prevalence in urban residents ( $>6$ years) of Shanghai increased by $1.4 \%$ from 1997 to 2007 (4). Asthma prevalence among Hong Kong schoolchildren (13-14 years) decreased by $1 \%$ from 1995 to 2002 (5). According to a study of the elderly aged $\geq 70$ years in Hong Kong, little changes in the prevalences of asthma (5.1\% in 1991 vs. $5.8 \%$ in 2003) and chronic bronchitis (6.7\% in 1991 vs. $7.7 \%$ in 2003) were reported (6). In general, evidence regarding the temporal change in the prevalence of Chinese adults' respiratory disease is scarce and current findings remain inconsistent.

There is no doubt that the causes of changes in adults' respiratory health outcomes over a long time period are multifactorial (8), but it could be in part explained by the change in the levels of air pollution exposure $(9,10)$. Current literature provides ample evidence on the adverse effects of both ambient and indoor air pollution exposure on the respiratory health among Chinese adults (11-13). Associations between ambient air pollutants (e.g., particulate matter, ozone, and sulfur dioxide) and adults' respiratory outcomes, including lung function (12), respiratory diseases mortality (11) and morbidity (13), have been established among Chinese adults in a number of epidemiological research. For indoor air pollution-associated respiratory risks, most studies focused on pollution emissions from diverse indoor smoke, originating from cooking, heating, and tobacco smoke, etc. (14-17).

Due to the conduction of a series of air pollution control measures (18), ambient air pollution in most areas of China has gradually improved (19) or changed in terms of its composition (13) over the past two decades (20). Household air pollution, though still very high in some rural areas of China (21), appears to be experiencing a moderate improvement, as a result of several public health interventions such as the use of clean fuel and implementing efficient cookstoves $(22,23)$. Recently, a limited number of studies attempted to assess the health benefits related to specific air pollution interventions among Chinese population $(17,24,25)$. For example, with strict air pollution controls implemented during the 2008 Summer Olympic Games, a significant reduction in asthma outpatient visitis ( $\mathrm{RR}=0.54,95 \%$ CI: 0.39-0.75) among Beijing adults was observed during the Games, as compared with the baseline (before any air pollution controls) (25). A cohort study of about 280,000 Chinese never-smokers observed lower risk of respiratory outcomes among participants who switched to clean fuel or use of ventilated cookstoves than those who did not (17).

Similarly, studies were conducted in other countries to investigate a variety of health gains attributed to longterm improvement of ambient air pollution (26-28). For example, a children cohort study demonstrated that the reduction in long-term ambient air pollution exposures was associated with improvements in children's respiratory health in southern California (26). Another study of more than 200 United States counties also found that the reduction in ambient $\mathrm{PM}_{2.5}$ was significantly associated with improvements in residents' life expectancy during the 1980s and 1990s (27).

While separate evidence is apparent that human health gains are associated with the improvements in either ambient or indoor air pollution exposures, little is known about the potential health benefits when multiple air pollution exposures are considered simultaneously. In this study, we used data from the two cross-sectional surveys 
spanning over 20 years to investigate whether the change in adults' respiratory disease prevalence was associated with the changes in indoor and outdoor air pollution levels across four Chinese cities. We present the following article in accordance with the STROBE reporting checklist (available at https://dx.doi.org/10.21037/jtd-20-2121).

\section{Methods}

During 1993 and 1996, a cross-sectional study was performed to examine respiratory health effects of household-related characteristics and ambient air pollution among elementary school children in four Chinese cities $(29,30)$. Information for parents of study children was also collected, including education attainment, respiratory disease, and smoking status. The rapid urbanization and industrialization in Chinese cities over the past decades have been in conjunction with great changes in many aspects of people's living environment (such as ambient air pollution and housing type). Between 2017 and 2018, we conducted another cross-sectional study in the same four cities to assess the temporal variation of respiratory health outcomes and potential risk factors. Similar information on school children and their parents was obtained, mostly based on an assessment of questionnaire responses. The 1993-1996 study was termed as Period 1 study, and the 2017-2018 study as Period 2 study. In both periods, parents reported whether or not they had asthma, chronic bronchitis, and tuberculosis. Since tuberculosis prevalence was pretty low $(<1 \%)$, tuberculosis was not considered in our analysis. In this paper, we analyzed the parents' data from both periods to examine whether the changes in prevalences of respiratory diseases were associated with the changes in outdoor air pollution and several indoor air pollution surrogates.

\section{Questionnaire survey and indoor air pollution surrogates}

We conducted surveys in four Chinese cities-Chongqing, Wuhan, Lanzhou, and Guangzhou-in both studies. In Period 1 study, we selected two elementary schools, one from the urban and the other from the suburb area within each of the four cities. In Period 2 study, we attempted to select the same schools or schools located as close as possible to the schools in Period 1 for three of the four cities (Chongqing, Wuhan, and Lanzhou). Since the originally selected school was closed in the suburb of Guangzhou in Period 2, we instead selected a different school in the suburb of Shenzhen city, which is about
$140 \mathrm{~km}$ from Guangzhou. The survey study in Period 2 was approved by the Institutional Review Board of Duke Kunshan University (No. FWA00021580). The study was conducted in accordance with the Declaration of Helsinki (as revised in 2013).

In both periods, we administered questionnaires to the participating families to collect information. The questionnaire used in Period 2 contained mostly the same questions as in the Period 1, with exceptions on questions that were no longer relevant in Period 2, for example, wood was no longer included as an option of the question of cooking fuel in Period 2. Parents of the participating school children were required to fill out the questionnaires themselves with help from our field investigators. The survey included questions on parents' respiratory diseases, socioeconomic status, smoking status and household characteristics.

Respondents were invited to report physician-diagnosed asthma and chronic bronchitis. They were all "Yes" or "No" questions. Respondents' socioeconomic status were represented by education attainment and occupation type by asking multiple-choice questions with different options between studies of Periods 1 and 2, respectively. Thus, we aggregated the multiple options and generated consistent answers. We considered a dichotomized variable for education-whether the college-level degree was achieved, and a categorical variable for occupation including bluecollar (e.g., farmer, factory or industrial worker), whitecollar (e.g., nurse, doctor, and government administrative workers), and other types of occupation (e.g., military and the unknown). Although the exact ages of participants were not available, we supposed the age distributions of the two populations from two periods were comparable since they were both parents of children aged 6-13.

In the current study, we considered smoking exposure and household characteristics (kitchen type, cooking with coal as fuel and ventilation when cooking) as the indoor air pollution surrogates. For each question about household characteristics, while we asked three questions corresponding to three age ranges (i.e., younger than 3 -year-old, 3 to 6 years old, and older than 7 -year-old) of children in Period 1, parents in Period 2 were invited to answer just one general question. To ensure that answers to these questions from two surveys were appropriate, for each household in Period 1, we only considered the answer for the age range which contains the current age of child in that household whose information was collected. Active smoking exposure was determined by smoking-related "Yes" or 
"No" questions. Female/Male participants were defined as exposed to passive smoking at home if their husbands/wives were classified as current smokers. We could not determine the exposure time or the frequency for passive exposure, as detailed information on active smoking for participants was not available in this study.

\section{Outdoor air pollution}

We considered ambient concentrations of $\mathrm{PM}_{2.5}, \mathrm{PM}_{10}$, and $\mathrm{SO}_{2}$ as these data were available in both periods. We used the average concentrations of several years before conducting the questionnaire surveys to represent a typical level of ambient air pollution of each study period (29). In Period 1 study, we obtained data for $\mathrm{SO}_{2}$ from municipal monitoring stations for each district from 1993 to 1996. We specifically measured the levels for PM2.5 and PM10 in the schoolyards during 1995 and 1996. This is because size-fractionated particulate matters were not the regulated pollutants at that time and then not available from the municipal monitoring system. Based on daily measurements, we calculated 2-year average concentrations for $\mathrm{PM}_{2.5}$ and $\mathrm{PM}_{10}$ and 4-year average concentration for $\mathrm{SO}_{2}$ for the eight study districts. In Period 2, data for $\mathrm{PM}_{2.5}, \mathrm{PM}_{10}$, and $\mathrm{SO}_{2}$ were all obtained from a publicly available website (https://www.aqistudy.cn). This website provides monitored concentrations of regulated air pollutants for more than 300 Chinese cities. Since the air pollution data were only monitored at city level, the urban and suburban areas within a given city were assigned the same concentrations of air pollution in Period 2. We calculated 4-year (2014-2017) average concentrations for $\mathrm{PM}_{2.5}, \mathrm{PM}_{10}$, and $\mathrm{SO}_{2}$ in Period 2.

\section{Statistical analysis}

We conducted a two-stage analysis on the associations of the district-specific prevalences of respiratory diseases with the proportion of indoor air pollution surrogates and the concentrations of outdoor ambient air pollution. In the first stage of the analysis, we fit the following logistic regression model [Eq. 1] to calculate the adjusted prevalences of respiratory diseases among men and women in each district, adjusting for participants' education and occupation status. The model was fit separately for Period 1 and Period 2.

$$
\operatorname{Logit}\left[E\left(Y_{i j}\right)\right]=\beta_{0}+\beta_{1} \text { District }_{j}+\beta_{2} \text { Degree }_{i j}+\beta_{3} \text { Occupation }_{i j}
$$

* $\quad \mathrm{Y}_{\mathrm{ij}}$ is an indicator variable denoting whether or not participant $\mathrm{i}$ in District $\mathrm{j}$ had respiratory diseases, with $Y_{i j}=1$ for having self-reported disease and $Y_{i j}=$ 0 for none;

* $\quad \beta_{0}$ is the model intercept;

* District ${ }_{j}$ is a dummy variable for the eight study districts within four cities, and $\beta_{1}$ is a vector of coefficients for District, $j=1, \ldots, 8$. Based on the estimated coefficients $\left(\beta_{0}, \beta_{1}\right)$, we calculated the adjusted district-specific diseases prevalences for each study periods (29);

* $\quad$ Degree $_{i j}$ is an indicator variable denoting whether or not participant $i$ in District $j$ had obtained a college-level degree;

* Occupation $_{\mathrm{ij}}$ is an indicator variable denoting the occupation category of participant $i$ in District $j$.

In the second stage, we fit a first-difference regression model (27) with the district-level data, including the adjusted disease prevalence by district (calculated from the first stage analysis), ambient air pollution, and the proportion of indoor air pollution surrogates (i.e., cooking with coal, cooking ventilation, kitchen type, and smoking). The first-difference regression model is essentially a typical linear regression model, but, instead of using the directly measured data of a health outcome as the dependent variable and a risk factor as the independent variable, this model uses the differences (mostly overtime) in the dependent variable and in the independent variable. So this model can estimate the relationship between the change in disease prevalence and the change in a potential risk factor. We first calculated the differences of these district-level variables $(\Delta \mathrm{X}$ and $\Delta \mathrm{Y})$ between two periods. We used the values of differences to fit the following linear regression model [Eq. 2], separately for each respiratory disease among men and women.

$$
\Delta \mathrm{Y}_{\mathrm{j}}=\alpha_{0}+\alpha_{1} \Delta \mathrm{X}_{\mathrm{j}}
$$

where:

* $\Delta Y_{\mathrm{j}}$ is the difference of respiratory disease prevalences between two study periods for district $j$, $\mathrm{j}=1, \ldots, 8$;

* $\quad \alpha 0$ is the model intercept;

* $\Delta \mathrm{Xj}_{\mathrm{j}}$ is the difference of a certain environmental risk factor for district $\mathrm{j}$. These risk factors included the concentration of outdoor air pollution and the proportion of selected indoor air pollution surrogates. $\alpha_{1}$ is the estimated linear coefficient for the relationship between the change in the

where: 
Table 1 Characteristics of households and participants in Period 1 and Period 2

\begin{tabular}{|c|c|c|c|c|}
\hline & \multicolumn{2}{|c|}{ Period 1} & \multicolumn{2}{|c|}{ Period 2} \\
\hline Households in total & 4571 & 3,183 & 5,743 & 3,907 \\
\hline Separate kitchen & $2,290(50.1)$ & $2,201(69.1)$ & $2,807(48.9)$ & $1,910(48.9)$ \\
\hline Cooking with coal as fuel & $973(21.3)$ & $962(30.2)$ & $114(2.0)$ & $115(2.9)$ \\
\hline \multicolumn{5}{|l|}{ Male } \\
\hline Smoking & $3,548(77.6)$ & $2,252(70.8)$ & $2,567(44.7)$ & $1,607(41.1)$ \\
\hline College-level education & $858(18.8)$ & $839(26.4)$ & $1,860(32.4)$ & $1,216(31.1)$ \\
\hline \multicolumn{5}{|l|}{ Occupation } \\
\hline \multicolumn{5}{|l|}{ Female } \\
\hline Smoking & $71(1.6)$ & $23(0.7)$ & $36(0.6)$ & $84(2.1)$ \\
\hline College-level education & $445(9.7)$ & $527(16.6)$ & 1,776 (30.9) & $1,120(28.7)$ \\
\hline \multicolumn{5}{|l|}{ Occupation } \\
\hline Blue collar & $2,117(46.3)$ & $1,819(57.1)$ & $1,258(21.9)$ & $1,166(29.8)$ \\
\hline White collar & $2,045(44.7)$ & $1,188(37.3)$ & 2,306 (40.2) & $1,792(45.9)$ \\
\hline
\end{tabular}

respiratory disease prevalence and the change in a certain potential environmental risk factor over two periods.

To examine the influence on the change in disease prevalence over time associated with several environmental risk factors simultaneously, we fit multiple linear regression in the second stage, with more than one independent variable (i.e., $\Delta \mathrm{X}_{1, \mathrm{j}}$ and $\Delta \mathrm{X}_{2, \mathrm{j}}$ ) included in the model. As a sensitivity analysis, we also fit the individual cross-sectional regression models, using the district-level data of each period rather than the difference between the two periods. All the statistical analyses were conducted using $\mathrm{R}$ software (version 4.0.3; R Development Core Team).

\section{Results}

\section{Indoor air pollution surrogates}

In both periods, we achieved reasonably high response rates. In study Period 1, we distributed a total of 7,621 questionnaires in the eight schools selected in the four Chinese cities and received 7,557 back to reach a $99.2 \%$ response rate. In Period 2, 11,449 questionnaires were distributed, and 9,974 subjects returned, with an overall response rate of $87.1 \%$.

Compared to Period 1, the proportion of cooking with coal as fuel largely decreased in Period 2 (Table 1), especially in the suburban of Wuhan and Lanzhou, with the decreases of $32.5 \%$ (38.6\% vs. $6.1 \%)$ and $89.7 \%(92.0 \%$ vs. $2.3 \%)$, respectively (Table S1). In contrast, more households were using cooking ventilation in Period 2 (an overall prevalence was $92.3 \%)$ than Period 1 (61.6\%, Table 1). These changes in cooking fuel and ventilation suggest that cooking-related indoor air pollution have generally improved from Period 1 to period 2 in the four cities. We observed noticeable changes in the proportion of separate kitchen in some of the eight districts across the two study periods (Table 1). For example, in suburban Guangzhou, the proportions of owing separate kitchens decreased from $68.5 \%$ (Period 1) to $26.2 \%$ (Period 2; Table S1). Males' smoking prevalence had substantially decreased in all eight districts recently as compared with 20 years ago (Table 1, Table S2). Smoking prevalence of women generally reduced as well, with the 
Table 2 District-specific ambient air pollutant concentrations $\left(\mathrm{mg} / \mathrm{m}^{3}\right)$ in study Period 1 and Period 2

\begin{tabular}{|c|c|c|c|c|c|c|c|}
\hline City & District & \multicolumn{2}{|c|}{$\mathrm{PM}_{2.5}$} & \multicolumn{2}{|c|}{$\mathrm{PM}_{10}$} & \multicolumn{2}{|c|}{$\mathrm{SO}_{2}$} \\
\hline \multirow[t]{2}{*}{ Chongqing } & Urban & $94.2(54.1)$ & \multirow{2}{*}{$54.1(33.9)$} & $147.8(72.8)$ & \multirow{2}{*}{82.5 (44.6) } & 330.5 (160.6) & \multirow{2}{*}{$16.1(9.7)$} \\
\hline & Suburban & $82.1(46.2)$ & & 112.5 (58.2) & & $149.3(82.7)$ & \\
\hline Wuhan & Urban & 72.9 (51.8) & $64.4(42.9)$ & $128.6(74.9)$ & $99.7(53.0)$ & 72.5 (61.9) & $18.4(13.9)$ \\
\hline \multirow[t]{2}{*}{ Lanzhou } & Urban & $115.1(100.1)$ & \multirow{2}{*}{$51.5(26.5)$} & $222.4(150.4)$ & \multirow{2}{*}{$117.3(66.4)$} & $130.5(134.4)$ & \multirow{2}{*}{$21.5(14.0)$} \\
\hline & Suburban & 97.7 (73.7) & & $164.6(100.3)$ & & $54.0(61.5)$ & \\
\hline \multirow[t]{2}{*}{ Guangzhou } & Urban & $142.3(90.3)$ & $29.5(21.4)$ & $232.0(108.2)$ & $48.4(29.0)$ & $55.3(38.3)$ & $8.2(5.5)$ \\
\hline & Suburban & 69.7 (39.2) & 39.4 (16.2) & $116.9(65.9)$ & $60.5(23.3)$ & $41.4(32.1)$ & $13.2(2.7)$ \\
\hline
\end{tabular}

*, In Period 2, city-wide average concentrations were used for Chongqing, Wuhan, Lanzhou, as well as the urban district of Guangzhou. The suburban concentrations of Guangzhou were obtained using the city average concentration of Shenzhen. Mean and standard deviation (in parentheses) in study Period 1 are calculated using daily average concentrations during $1993-1996$ for SO ${ }_{2}$ and $1995-1996$ for $\mathrm{PM}_{2.5}$ and $\mathrm{PM}_{10}$. In study Period 2, summarized data for air pollutants are based on daily average concentrations during $2014-2017$.

exception of suburban Guangzhou (Table 1, S2).

\section{Outdoor air pollution concentrations in two study periods}

Outdoor air pollution in the four Chinese cities, especially in the urban area, has greatly improved from Period 1 to Period 2 (Table 2). While particulate matter levels in Period 1 were extremely high in Lanzhou and Guangzhou, they decreased by a factor of more than two in Period 2 study. For example, in contrast to a 2-year (1995-1996) average concentration of $232.0 \mu \mathrm{g} / \mathrm{m}^{3}$ for $\mathrm{PM}_{10}$ in urban Guangzhou, the average concentration (2014-2017) of $\mathrm{PM}_{10}$ in Period 2 was $48.4 \mu \mathrm{g} / \mathrm{m}^{3}$. Chongqing suffered from severe pollution of $\mathrm{SO}_{2}$ in the late of last century, with a four-year average (1993-1996) of $330.5 \mu \mathrm{g} / \mathrm{m}^{3}$ in the urban district. But in recent years, $\mathrm{SO}_{2}$ in the urban area of Chongqing greatly decreased to $16.1 \mathrm{\mu g} / \mathrm{m}^{3}$ (the 4-year average during the period of 2014-2017). Since we did not obtain district-specific concentrations for each city in Period 2, we could not compare outdoor air pollution variations over the twenty years for urban and suburban separately.

\section{Adjusted prevalences of asthma and chronic bronchitis}

College-level education attainment was more prevalent among participants in Period 2 than those in Period 1 (Table 1, Table S2). The proportion of "blue-collar" participants was approximately halved from Period 1 to 2 in both urban and suburban districts (Table 1, Table S2). With the adjustment for participants' education and occupation, the district-specific prevalences of asthma and chronic bronchitis for both men and women were decreased by an average of $3.6 \%$ (range: $0.0 \%$ to $24.3 \%$ ) in Period 2 versus Period 1 (Figure 1). In general, the decrease in the prevalence of chronic bronchitis was larger than that of asthma. For example, in the urban district of Lanzhou, the adjusted prevalence of chronic bronchitis decreased substantially from $24.8 \%$ to $2.9 \%$ and the adjusted prevalence of asthma decreased from $2.5 \%$ to $0.8 \%$ from Period 1 to Period 2 among the male participants (Figure 1).

\section{Effects of air pollution on disease prevalence}

Among the indoor air pollution surrogates investigated in the study, we found that the decrease in the proportion of cooking with coal might be an important contributor to the reduction in respiratory disease prevalence among our participants over the periods. According to the firstdifference regression model (the second stage analysis), one percent decrease in the proportion of cooking with coal was associated with a $19.0 \%$ (95\% CI, 1.0-37.0\%) decrease in the prevalence of males' chronic bronchitis across the eight districts (Table 3). This substantial association was also confirmed by several multiple regressions when other air pollution variables were included in the models (Table 4). The decrease in the proportion of cooking with coal over 

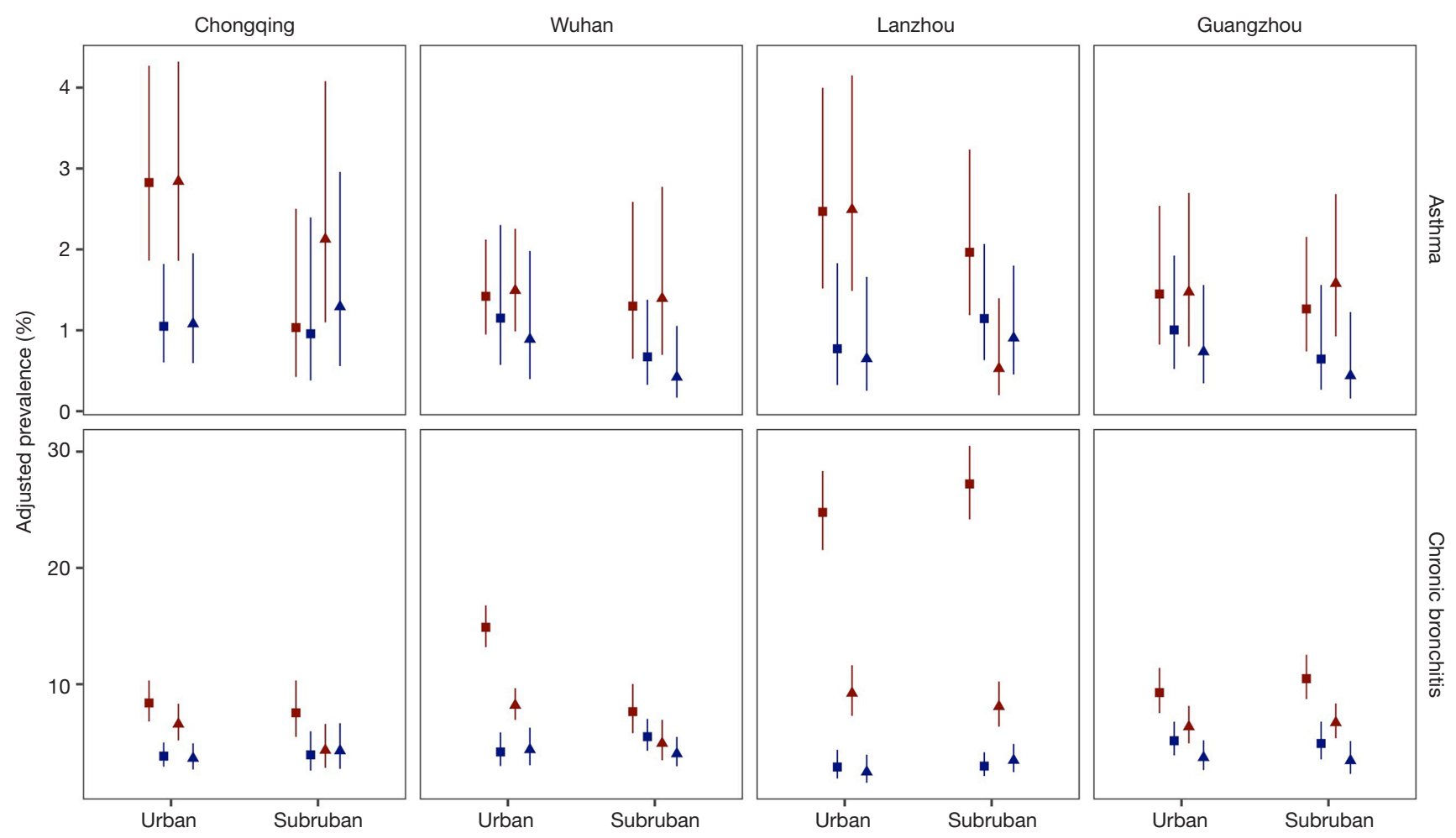

$\uparrow$ Period 1, Men $\$$ Period 2, Men $\uparrow$ Period 1, Women $\$$ Period 2, Women

Figure 1 District-specific adjusted prevalences (\%) and 95\% confidence intervals (vertical lines) of asthma and chronic bronchitis for men and women in study Period 1 and Period 2, calculated using the reference levels of "below college-level education" for education and "blue collar" for occupation.

Table 3 Estimates and 95\% CI (in parentheses) of the change in respiratory disease prevalence (\%) associated with $1 \%$ decrease in the prevalence of indoor air pollution surrogates or an interquartile range (IQR) decrease in outdoor air pollutant concentration

\begin{tabular}{|c|c|c|c|c|}
\hline & \multicolumn{2}{|c|}{ Male } & \multicolumn{2}{|c|}{ Female } \\
\hline \multicolumn{5}{|c|}{ Indoor air pollution surrogate } \\
\hline Active smoke & $-2.83(-10.34,4.67)$ & $31.42(-74.46,137.3)$ & $-0.04(-22.36,22.27)$ & $-1.10(-67.87,65.68)$ \\
\hline Passive smoke & $4.80(-14.82,24.41)$ & $33.33(-242.68,309.34)$ & $-4.71(-12.61,3.19)$ & $-2.74(-28.86,23.37)$ \\
\hline Cooking coal & $-0.11(-1.81,1.59)$ & $19.00(0.96,37.04)$ & $-1.86(-3.04,-0.69)$ & $2.00(-3.45,7.45)$ \\
\hline Cooking ventilation & $-0.29(-2.78,2.21)$ & $-17.49(-49.32,14.35)$ & $1.10(-1.56,3.76)$ & $-4.09(-11.8,3.62)$ \\
\hline \multicolumn{5}{|l|}{ Outdoor air pollutant } \\
\hline $\mathrm{PM}_{2.5}$ & $0.11(-0.34,0.55)$ & $1.55(-4.62,7.72)$ & $0.02(-0.48,0.53)$ & $0.66(-0.76,2.08)$ \\
\hline
\end{tabular}

The IQRs for $\mathrm{PM}_{2.5}, \mathrm{PM}_{10}$ and $\mathrm{SO}_{2}$ are 34,51 , and $43 \mathrm{mg} / \mathrm{m}^{3}$, respectively. 
Table 4 Estimates and $95 \%$ CI (in parentheses) of the change in males' respiratory disease prevalence (\%) associated with a $1 \%$ decrease in the prevalence of indoor air pollution surrogates or an interquartile range (IQR) decrease in outdoor air pollutant concentrations, based on multiple linear regression models

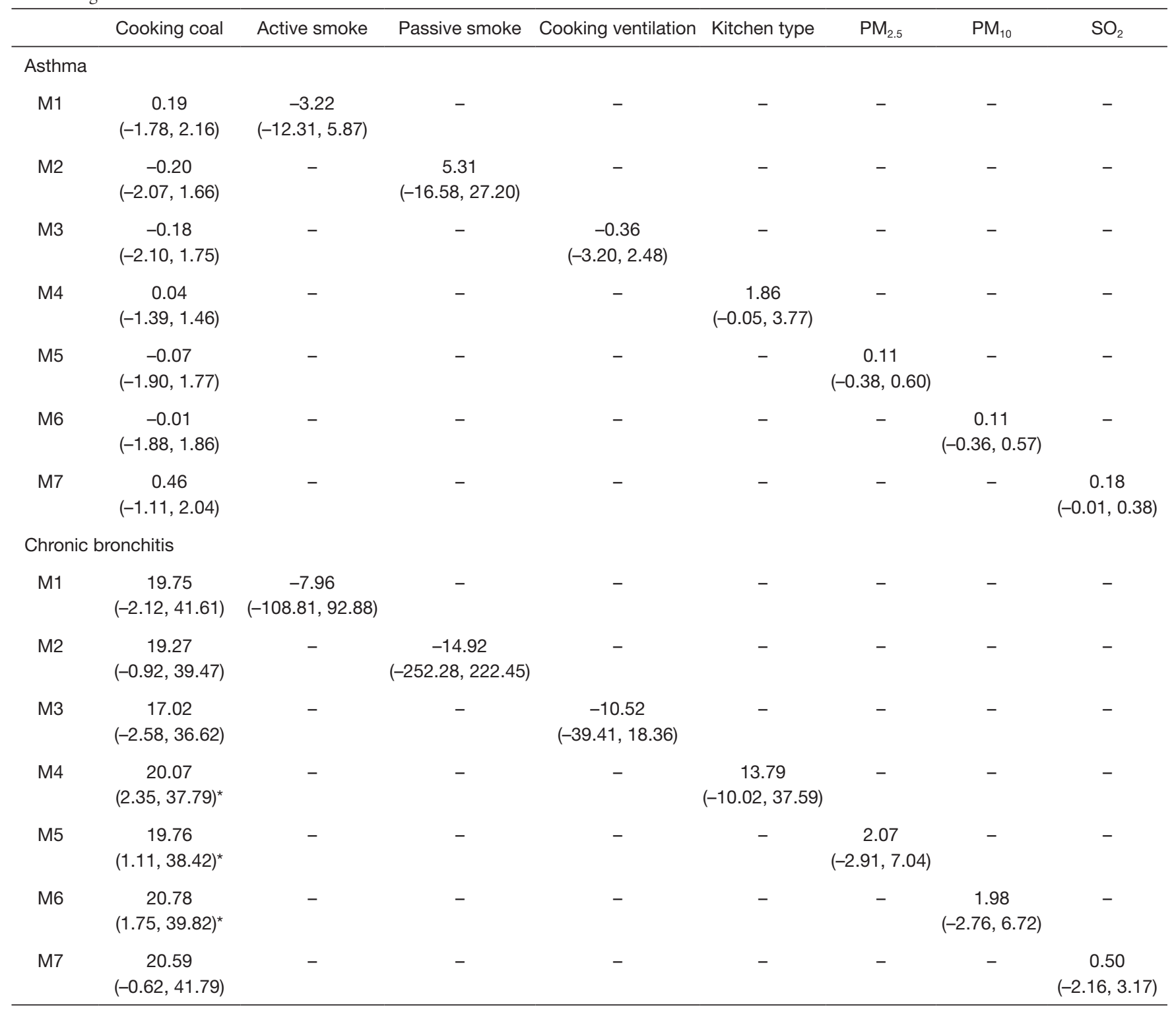

*, $\mathrm{P}<0.05$. "M1" to "M7" in the first column represented seven models, including the difference of the proportion of "cooking coal" and the difference of another environmental risk factor as listed by column. The IQRs for $\mathrm{PM}_{2.5}, \mathrm{PM}_{10}$, and $\mathrm{SO}_{2}$ are 34,51 , and $43 \mathrm{mg} / \mathrm{m}^{3}$, respectively.

time was also significantly, but negatively, associated with the decrease in the prevalence of females' asthma (Tables 3,5). And this association did not change in terms of significance after adjusting for other air pollution variables (Tables 3,5). Although the decrease in the proportion of cooking with coal also had a positive association with the prevalence of females' chronic bronchitis and a negative association with the prevalence of males' asthma, these associations were very small and non-significant. There was little evidence of associations between the change in other indoor air pollution surrogates and the change in respiratory disease prevalences across the eight study districts.

With regard to outdoor air pollution, although these estimates were not statistically significant, a few suggestive 
Table 5 Estimates and 95\% CI (in parentheses) of the change in females' respiratory disease prevalence (\%) associated with a $1 \%$ decrease in the prevalence of indoor air pollution surrogates or an interquartile range (IQR) decrease in outdoor air pollutant concentrations, based on multiple linear regression models

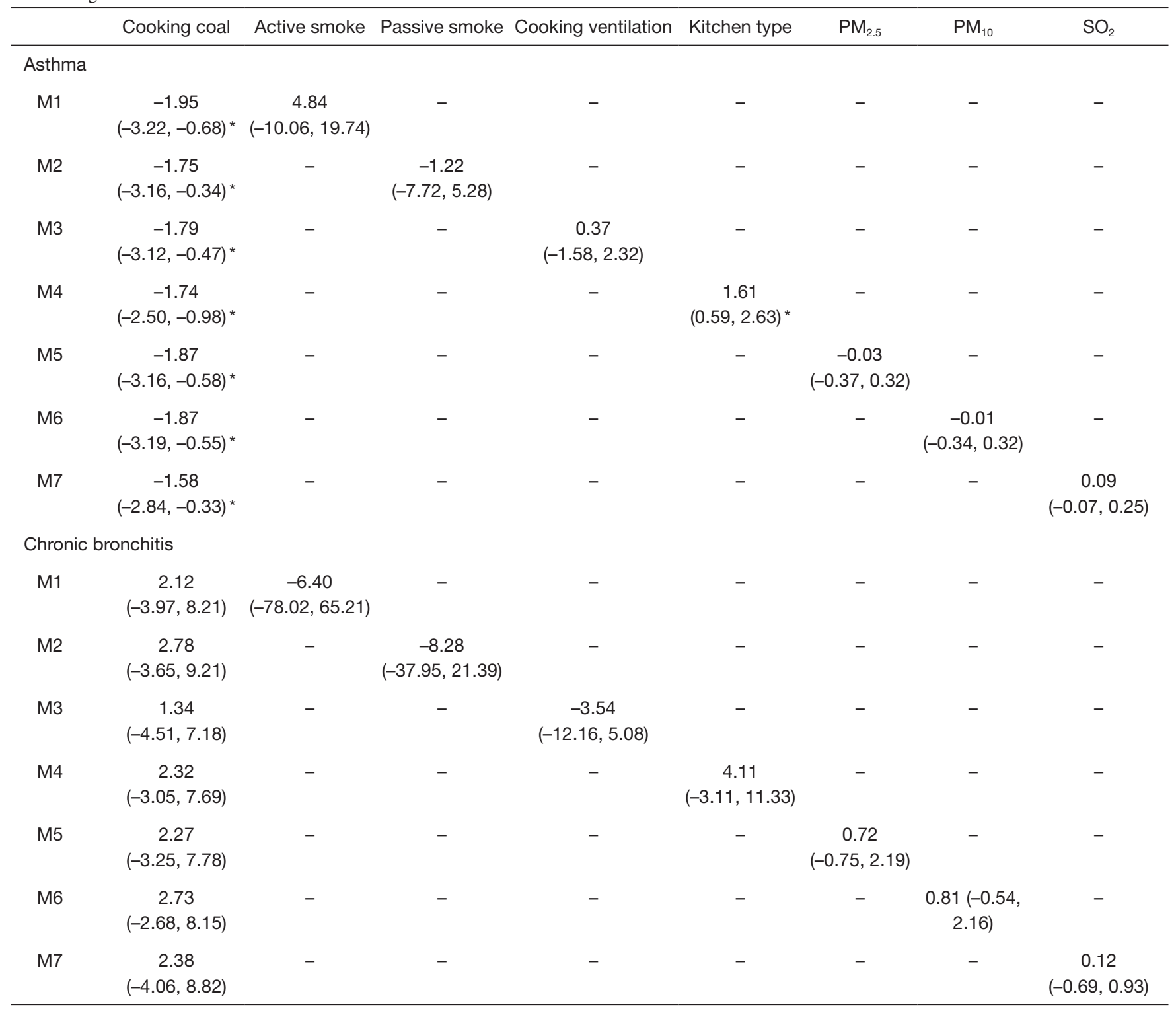

*, $\mathrm{P}<0.05$. "M1" to "M7" in the first column represented seven models, including the difference of the proportion of "cooking coal" and the difference of another environmental risk factor as listed by column. The IQRs for $\mathrm{PM}_{2.5}, \mathrm{PM}_{10}$, and $\mathrm{SO}_{2}$ are 34,51 , and $43 \mathrm{mg} / \mathrm{m}^{3}$, respectively.

findings might be worth pointing out. First, in some cases, positive associations were consistently estimated from both primary and sensitivity analyses. For example, the decrease in $\mathrm{SO}_{2}$ seemed positively associated with the decrease in females' asthma prevalence. In addition, the effect size of decreased ambient air pollutants concentrations on the decrease in the prevalences of respiratory diseases was nearly the same for $\mathrm{PM}_{2.5}$ and $\mathrm{PM}_{10}$ (Tables 4,5), which could be resulted from the similar extent of change in the concentrations of $\mathrm{PM}_{2.5}$ and $\mathrm{PM}_{10}$ over the two periods.

\section{Sensitivity analysis}

Estimates from sensitivity analyses of fitting cross- 
sectional regression models were somewhat consistent with these primary results (Table S3). Based on crosssectional regression models, we found that the decrease in the proportion of cooking with coal as fuel was positively associated with the decrease in the prevalence of males' chronic bronchitis, and negatively associated with the decrease in the prevalence of females' asthma in both periods.

\section{Discussion}

In the current study, we observed apparent decreases in the district-specific prevalences of asthma and chronic bronchitis for both male and female adults in four Chinese cities across more than two decades from 1993-1996 to 2017-2018, and the changes may be attributable to multiple factors. The most significant risk factor observed in the study was the change in the proportion of cooking with coal. We found that changes in the proportion of cooking with coal were positively related to the changes in the prevalence of males' chronic bronchitis, but negatively associated with the changes in the prevalence of females' asthma. In this study, we also found a substantial reduction in the concentrations of outdoor air pollutants investigated across the four Chinese cities in Period 2 compared with Period 1; however, little evidence was recognized regarding potential health gains associated with the decrease in ambient air pollution levels.

Through the comparison between the two periods, the decrease in the proportion of coal use for cooking was positively related to the decrease in the prevalence of males' chronic bronchitis (Tables 3,4). This result seems fairly rational, as the adverse health effect of indoor air pollution from solid fuel has been well characterized $(31,32)$. This result is also somewhat in line with previous findings of the potential health benefits, respiratory health in particular, associated with either switching from unclean cookfuels to clean cookfuels at home $(17,33)$ or the cessation of unclean cookfuels such as coal $(16,34)$. For example, a large cohort study (17) of Chinese adults found that, during the nine years follow-up, the hazard ratios (HR) for both acute and chronic respiratory diseases were significantly stronger among participants who used solid fuels (i.e., coal or wood) persistently than those who switched from solid fuel to clean fuels (i.e., electricity or gas).

Although this finding could provide suggestive evidence of respiratory health benefits when reducing the use of coal for cooking, caution should be taken when interpreting this notable estimate: the prevalence of males' bronchitis would decrease $20 \%$ per $1 \%$ decrease in the proportion of coal use across the eight districts. With measurements from two cross-sectional surveys, we were assuming a linear relationship between the decrease in the proportion of coal use and the decrease in disease prevalence. It is very likely that the true relationship between them is non-linear; in other words, the decrease of disease prevalence may depend on how much the proportion of coal use has decreased. To help validate this hypothesis, we conducted an additional analysis using the data of the present study. Among the eight study districts, households from the suburban of Lanzhou experienced the largest decrease in the proportion of cooking with coal, from $92 \%$ in Period 1 to $2.3 \%$ in Period 2 (Table S1). When excluding the suburban of Lanzhou, we obtained a $4.5 \%$ decrease in the bronchitis prevalence for men per reduction of $1 \%$ in the prevalence of cooking with coal, which is much smaller than the estimate (about $20 \%$ ) using all the data. Further study can be conducted to investigate the potential beneficial effect of the reduction of coal use at home on respiratory diseases like chronic bronchitis.

From Period 1 to Period 2, the decrease in the proportion of coal use for cooking was significantly but negatively associated with the decrease in the prevalence of asthma among women in our study. This relationship remained negative even we excluded the data from the suburban of Lanzhou, where the reduction in the use of coal for cooking was extremely large. The current evidence seems not consistently support a deleterious effect of coal use for cooking on adults with asthma (35-39). For example, a cross-sectional survey found that coal use for cooking was an important risk factor for asthma prevalence, with an estimated odds ratio of 2.65 (95\% CI, 1.26-5.57), among nearly 10,000 residents aged 15 and over in seven Chinese cities in 2012 (35). Similar findings were also reported in another survey conducted in a heavyindustry province in China, which reported an OR of 1.45 (95\% CI, 1.10-1.90) for the use of coal at home compared with those who did not use coal (37). However, there also exists evidence of little or no association between coal use at home and asthma $(38,39)$. For example, a recent multicountry prospective study did not observe a heightened risk for asthma associated with household solid fuel use (such as coal and wood), as compared with clean fuel (such as gas and electricity) (39).

A possible explanation for the observed negative relationship between the decrease in coal use proportion 
and the decrease in asthma prevalence over the two study periods may be due to other confounding variables that have also varied greatly over the two periods and not considered in our analysis. Urbanization (also known as urbanicity) could be an important one. A growing number of studies have found that urbanization is positively related to asthma prevalence among both children and adults in several parts of the world (40-43). The adverse impact of urbanization on asthma may be attributed to the elevated traffic-related air pollution, increased exposure to allergens (such as pollen), and Western-style diet (41-43). Urbanization is especially associated with a high risk of asthma in areas where the baseline of urbanization is low (40). Meanwhile, there is evidence that residential coal use is negatively related to urbanization in China over the recent decades $(44,45)$. Taken together, it seems reasonable to spectulate that, from the study Period 1 to Period 2, the rapid urbanization in Chinese cities is related to a decrease in the coal use at home and an increase in the asthma prevalence, which could help to explain our finding of a negative relationship between coal use and asthma prevalence.

While the two diseases investigated in the current study-chronic bronchitis and asthma-present several common characteristics, we indeed observed different associations between the change in the proportion of coal use for cooking and the change in the disease prevalences in our study cities. This suggests that different disease phenotypes are related to unique primary risk factors; for example, some studies have indicated that solid fuel use at home has a stronger association with chronic bronchitis than other respiratory outcomes $(17,46)$. Therefore, targeted interventions are necessary for different disease phenotypes.

The ambient air pollution over two periods, though generally improved in the four cities, appeared to not contribute to the decrease in respiratory disease prevalences among study participants. Since the respiratory outcomes investigated were both chronic diseases and the crosssectional studies were not able to capture the onset or exacerbation of these respiratory diseases, our findings did not provide sufficient evidence regarding the respiratory health benefits related to the improvement of ambient air pollution. Similar findings were found in the existing literature. Based on a meta-analysis of multi-community prevalence studies, no asssociation between long-term exposure to outdoor air pollution, including $\mathrm{PM}_{10}$, ozone, sulfur dioxide, and nitrogen dioxide, and asthma prevalence was reported (47). By contrast, another meta-analysis of cohort studies found an increased risk for asthma incidence associated with long-term exposure to ambient $\mathrm{PM}_{2.5}$ (48). Further, in most Chinese cities, while the concentration of ambient particulate matter has been decreasing in the past decades, emerging evidence suggests the levels of ozone were increasing over time $(49,50)$. Previous studies found ambient ozone exposure was associated with an increased risk for respiratory diseases (51). Since the data for ambient ozone concentration were not available in our study Period 1, we were not able to assess the changes in ozone concentration over periods. Because both particulate matter and ozone have adverse respiratory health effects, it is possible that the estimated association between the decrease in PM concentration and the decrease in the respiratory disease prevalence could be confounded by the increase in ozone concentration.

Some limitations of this study must be mentioned. First, since the surveys focused on studying children's respiratory health and associated risk factors, limited data were collected on adults, such as age. Given that Chinese women's fertility pattern may have changed over a long time period, the age distributions among parents of children aged 6-13 could have also changed from Period 1 to Period 2. Even though we assumed that age distributions of adults in two periods could be comparable, it would be impossible to compare the disease prevalence in this study to others due to the exact ages of participants were not presented. Further, residual confounding can play a role in our estimates due to both imprecise measure of existing covariates in our model and the failure to control for other potential confounders that can be associated with the change in respiratory disease prevalence (such as the time period of disease diagnose and medical treatment received). Finally, because detailed information on smoking was unavailable, we could not assess either the amount or frequency of smoking exposure. So, caution should be taken when comparing our results with others derived from certain populations with different smoking exposures.

To summarize, we observed a decrease in the prevalences of asthma and chronic bronchitis in four Chinese cities over two periods spanning more than 20 years, after adjusting for participants' education and occupation. Since very limited data are available regarding the temporal change in the respiratory disease prevalence in China, our findings can add to the literature and provide evidence for future studies in this regard. Furthermore, our analysis found a significant association between the reduction in respiratory disease prevalence and the reduction in household coal 
use, suggesting eliminating this indoor air pollution source might be an important contributor to the improvement in respiratory health in adults living in the four Chinese cities. Although outdoor air pollution levels were substantially lower in the later period, changes in other risk factors may have masked ambient air quality improvement's health benefits. Future studies are recommended to ascertain these risk factors in their contributions to the changes in health conditions. Understanding the complex interplay of these factors and air pollution exposure will provide a more comprehensive strategy to improve people's respiratory health in Chinese cities that have undergone rapid economic and environmental changes.

\section{Acknowledgments}

Funding: Fund support from the 111 Project "Urban Air Pollution and Health Effects (B20009)" and Beijing Innovation Center for Engineering Science and Advanced Technology (BICESAT).

\section{Footnote}

Provenance and Peer Review: This article was commissioned by the Guest Editors (Junfeng Zhang, Howard Kipen and Haidong Kan) for the series "Children's Respiratory Health and Air Quality" published in Fournal of Thoracic Disease. The article has undergone external peer review.

Reporting Checklist: The authors have completed the STROBE reporting checklist. Available at https://dx.doi. org/10.21037/jtd-20-2121

Data Sharing Statement: Available at https://dx.doi. org/10.21037/jtd-20-2121

Conflicts of interest: All authors have completed the ICMJE uniform disclosure form (available at https:// dx.doi.org/10.21037/jtd-20-2121). The series "Children's Respiratory Health and Air Quality" was commissioned by the editorial office without any funding or sponsorship. JJZ served as the unpaid Guest Editor of the series. JG and JJZ serves as editorial board members of fournal of Thoracic Disease. The authors have no other conflicts of interest to declare.

Ethical Statement: The authors are accountable for all aspects of the work in ensuring that questions related to the accuracy or integrity of any part of the work are appropriately investigated and resolved. The study was conducted in accordance with the Declaration of Helsinki (as revised in 2013). Approval of study protocol was obtained from Duke Kunshan University IRB (No. FWA00021580). Informed consent was obtained from parents or guardians of participating children.

Open Access Statement: This is an Open Access article distributed in accordance with the Creative Commons Attribution-NonCommercial-NoDerivs 4.0 International License (CC BY-NC-ND 4.0), which permits the noncommercial replication and distribution of the article with the strict proviso that no changes or edits are made and the original work is properly cited (including links to both the formal publication through the relevant DOI and the license). See: https://creativecommons.org/licenses/by-nc-nd/4.0/.

\section{References}

1. Eder W, Ege MJ, von Mutius E. The asthma epidemic. N Engl J Med 2006;355:2226-35.

2. Anandan C, Nurmatov U, van Schayck OC, et al. Is the prevalence of asthma declining? Systematic review of epidemiological studies. Allergy 2010;65:152-67.

3. Zhang Y, Li B, Huang C, et al. Ten cities cross-sectional questionnaire survey of children asthma and other allergies in China. Chinese Science Bulletin 2013;58:4182-9.

4. Zhang F, Hang J, Zheng B, et al. The changing epidemiology of asthma in Shanghai, China. J Asthma 2015;52:465-70.

5. Wong GW, Leung TF, Ko FW, et al. Declining asthma prevalence in Hong Kong Chinese schoolchildren. Clin Exp Allergy 2004;34:1550-5.

6. Ko FW, Lai CK, Woo J, et al. 12-year change in prevalence of respiratory symptoms in elderly Chinese living in Hong Kong. Respir Med 2006;100:1598-607.

7. Lee YL, Lin YC, Hwang BF, et al. Changing prevalence of asthma in Taiwanese adolescents: two surveys 6 years apart. Pediatr Allergy Immunol 2005;16:157-64.

8. Levy JI, Quirós-Alcalá L, Fabian MP, et al. Established and Emerging Environmental Contributors to Disparities in Asthma and Chronic Obstructive Pulmonary Disease. Curr Epidemiol Rep 2018;5:114-24.

9. Guan WJ, Zheng XY, Chung KF, et al. Impact of air pollution on the burden of chronic respiratory diseases in China: time for urgent action. Lancet 2016;388:1939-51.

10. Jiang XQ, Mei XD, Feng D. Air pollution and chronic 
airway diseases: what should people know and do? J Thorac Dis 2016;8:E31-40.

11. Zhou M, He G, Liu Y, et al. The associations between ambient air pollution and adult respiratory mortality in 32 major Chinese cities, 2006-2010. Environ Res 2015;137:278-86.

12. Wu S, Deng F, Wang X, et al. Association of lung function in a panel of young healthy adults with various chemical components of ambient fine particulate air pollution in Beijing, China. Atmospheric Environment 2013;77:873-84.

13. Chen B, Hong C, Kan H. Exposures and health outcomes from outdoor air pollutants in China. Toxicology 2004;198:291-300.

14. Qian Z, He Q, Kong L, et al. Respiratory responses to diverse indoor combustion air pollution sources. Indoor Air 2007; 17:135-42.

15. Sana A, Somda SMA, Meda N, et al. Chronic obstructive pulmonary disease associated with biomass fuel use in women: a systematic review and meta-analysis. BMJ Open Respir Res 2018;5:e000246.

16. Lin HH, Murray M, Cohen T, et al. Effects of smoking and solid-fuel use on COPD, lung cancer, and tuberculosis in China: a time-based, multiple risk factor, modelling study. Lancet 2008;372:1473-83.

17. Chan KH, Kurmi OP, Bennett DA, et al. Solid Fuel Use and Risks of Respiratory Diseases. A Cohort Study of 280,000 Chinese Never-Smokers. Am J Respir Crit Care Med 2019;199:352-61.

18. Wang S, Hao J. Air quality management in China: issues, challenges, and options. J Environ Sci (China) 2012;24:2-13.

19. Wang S, Xing J, Zhao B, et al. Effectiveness of national air pollution control policies on the air quality in metropolitan areas of China. J Environ Sci (China) 2014;26:13-22.

20. Yin Z, Huang X, He L, et al. Trends in ambient air pollution levels and PM2.5 chemical compositions in four Chinese cities from 1995 to 2017 . J Thorac Dis 2020;12:6396-410.

21. Du W, Li X, Chen Y, et al. Household air pollution and personal exposure to air pollutants in rural China - A review. Environ Pollut 2018;237:625-38.

22. Zhao B, Zheng H, Wang S, et al. Change in household fuels dominates the decrease in PM2.5 exposure and premature mortality in China in 2005-2015. Proc Natl Acad Sci U S A 2018;115:12401-6.

23. Meng W, Zhong Q, Chen Y, et al. Energy and air pollution benefits of household fuel policies in northern
China. Proc Natl Acad Sci U S A 2019;116:16773-80.

24. Li S, Williams G, Guo Y. Health benefits from improved outdoor air quality and intervention in China. Environ Pollut 2016;214:17-25.

25. Li Y, Wang W, Kan H, et al. Air quality and outpatient visits for asthma in adults during the 2008 Summer Olympic Games in Beijing. Sci Total Environ 2010;408:1226-7.

26. Gauderman WJ, Urman R, Avol E, et al. Association of improved air quality with lung development in children. $\mathrm{N}$ Engl J Med 2015;372:905-13.

27. Pope CA 3rd, Ezzati M, Dockery DW. Fine-particulate air pollution and life expectancy in the United States. N Engl J Med 2009;360:376-86.

28. Garcia E, Berhane KT, Islam T, et al. Association of Changes in Air Quality With Incident Asthma in Children in California, 1993-2014. JAMA 2019;321:1906-15.

29. Zhang JJ, Hu W, Wei F, et al. Children's respiratory morbidity prevalence in relation to air pollution in four Chinese cities. Environ Health Perspect 2002;110:961-7.

30. Qian Z, Zhang J, Wei F, et al. Long-term ambient air pollution levels in four Chinese cities: inter-city and intracity concentration gradients for epidemiological studies. J Expo Anal Environ Epidemiol 2001;11:341-51.

31. Kurmi OP, Semple S, Simkhada P, et al. COPD and chronic bronchitis risk of indoor air pollution from solid fuel: a systematic review and meta-analysis. Thorax 2010;65:221-8.

32. Gordon SB, Bruce NG, Grigg J, et al. Respiratory risks from household air pollution in low and middle income countries. Lancet Respir Med 2014;2:823-60.

33. Staff Mestl HE, Aunan K, Seip HM. Potential health benefit of reducing household solid fuel use in Shanxi province, China. Sci Total Environ 2006;372:120-32.

34. Kim C, Seow WJ, Shu XO, et al. Cooking Coal Use and All-Cause and Cause-Specific Mortality in a Prospective Cohort Study of Women in Shanghai, China. Environ Health Perspect 2016;124:1384-9.

35. Fu QL, Du Y, Xu G, et al. Prevalence and Occupational and Environmental Risk Factors of Self-Reported Asthma: Evidence from a Cross-Sectional Survey in Seven Chinese Cities. Int J Environ Res Public Health 2016;13:1084.

36. Mishra V. Effect of indoor air pollution from biomass combustion on prevalence of asthma in the elderly. Environ Health Perspect 2003;111:71-8.

37. Wilson D, Takahashi K, Pan G, et al. Respiratory symptoms among residents of a heavy-industry province in China: prevalence and risk factors. Respir Med 
2008;102:1536-44.

38. Po JY, FitzGerald JM, Carlsten C. Respiratory disease associated with solid biomass fuel exposure in rural women and children: systematic review and meta-analysis. Thorax 2011;66:232-9.

39. Hystad P, Duong M, Brauer M, et al. Health Effects of Household Solid Fuel Use: Findings from 11 Countries within the Prospective Urban and Rural Epidemiology Study. Environ Health Perspect 2019;127:57003.

40. Son JY, Kim H, Bell ML. Does urban land-use increase risk of asthma symptoms? Environ Res 2015;142:309-18.

41. Gaviola C, Miele CH, Wise RA, et al. Urbanisation but not biomass fuel smoke exposure is associated with asthma prevalence in four resource-limited settings. Thorax 2016;71:154-60.

42. Rodriguez A, Brickley E, Rodrigues L, et al. Urbanisation and asthma in low-income and middle-income countries: a systematic review of the urban-rural differences in asthma prevalence. Thorax 2019;74:1020-30.

43. Robinson CL, Baumann LM, Romero K, et al. Effect of urbanisation on asthma, allergy and airways inflammation in a developing country setting. Thorax 2011;66:1051-7.

44. Zhao P, Zhang M. The impact of urbanization on energy consumption: A 30-year review in China. Urban Climate 2018;24:940-53.

Cite this article as: Yan M, Gong J, Liu Q, Li W, Duan X, Cao S, Li S, He L, Yin Z, Lin W, Jim Zhang JJ. The effects of indoor and outdoor air pollution on the prevalence of adults' respiratory diseases in four Chinese cities: a comparison between 2017-2018 and 1993-1996. J Thorac Dis 2021;13(7):4560-4573. doi: 10.21037/jtd-20-2121
45. Xie L, Yan H, Zhang S, et al. Does urbanization increase residential energy use? Evidence from the Chinese residential energy consumption survey 2012. China Economic Review 2020;59:101374.

46. Amaral AFS, Patel J, Kato BS, et al. Airflow Obstruction and Use of Solid Fuels for Cooking or Heating: BOLD Results. Am J Respir Crit Care Med 2018;197:595-610.

47. Anderson HR, Favarato G, Atkinson RW. Long-term exposure to outdoor air pollution and the prevalence of asthma: Meta-analysis of multi-community prevalence studies. Air Qual Atmos Health 2013;6:57-68.

48. Anderson HR, Favarato G, Atkinson RW. Long-term exposure to air pollution and the incidence of asthma: Meta-analysis of cohort studies. Air Qual Atmos Health 2013;6:47-56.

49. Wang WN, Cheng TH, Gu XF, et al. Assessing Spatial and Temporal Patterns of Observed Ground-level Ozone in China. Sci Rep 2017;7:3651.

50. Verstraeten WW, Neu JL, Williams JE, et al. Rapid increases in tropospheric ozone production and export from China. Nat Geosci 2015;8:690.

51. Ji M, Cohan DS, Bell ML. Meta-analysis of the Association between Short-Term Exposure to Ambient Ozone and Respiratory Hospital Admissions. Environ Res Lett 2011;6:024006. 


\section{Supplementary}

Table S1 District-specific characteristics of households in four Chinese cities in Period 1 and Period 2, showing number and proportion (\%, in the parentheses) for each parameter

\begin{tabular}{|c|c|c|c|c|c|}
\hline City & District & N & Separate kitchen & Cooking with coal as fuel & Cooking ventilation \\
\hline \multicolumn{6}{|l|}{ Chongqing } \\
\hline \multirow[t]{2}{*}{ Period 1} & Urban & 1011 & $459(45.4)$ & $67(6.6)$ & $675(66.8)$ \\
\hline & Suburban & 441 & $279(63.3)$ & $8(1.8)$ & $289(65.5)$ \\
\hline \multirow[t]{2}{*}{ Period 2} & Urban & 1599 & $786(49.2)$ & $14(0.9)$ & $1587(99.2)$ \\
\hline & Suburban & 527 & $239(45.4)$ & $6(1.1)$ & $524(99.4)$ \\
\hline \multicolumn{6}{|l|}{ Wuhan } \\
\hline \multirow[t]{2}{*}{ Period 1} & Urban & 1924 & $1040(54.1)$ & $664(34.5)$ & $739(38.4)$ \\
\hline & Suburban & 593 & $250(42.2)$ & $229(38.6)$ & $298(50.3)$ \\
\hline \multirow[t]{2}{*}{ Period 2} & Urban & 1985 & $841(42.4)$ & $71(3.6)$ & $1675(84.4)$ \\
\hline & Suburban & 1167 & $530(45.4)$ & $71(6.1)$ & $1058(90.7)$ \\
\hline \multicolumn{6}{|l|}{ Lanzhou } \\
\hline \multirow[t]{2}{*}{ Period 1} & Urban & 716 & $269(37.6)$ & $104(14.5)$ & $512(71.5)$ \\
\hline & Suburban & 767 & 726 (94.7) & 706 (92.0) & 736 (96.0) \\
\hline \multirow[t]{2}{*}{ Period 2} & Urban & 848 & $602(71.0)$ & $11(1.3)$ & $750(88.4)$ \\
\hline & Suburban & 1218 & $880(72.2)$ & $28(2.3)$ & 1108 (90.9) \\
\hline \multicolumn{6}{|c|}{ Guangzhou } \\
\hline \multirow[t]{2}{*}{ Period 1} & Urban & 920 & $522(56.7)$ & $138(15.0)$ & $891(96.8)$ \\
\hline & Suburban & 1382 & $946(68.5)$ & $19(1.4)$ & 1359 (98.3) \\
\hline \multirow[t]{2}{*}{ Period 2} & Urban & 1311 & $578(44.1)$ & $18(1.4)$ & $1287(98.2)$ \\
\hline & Suburban & 995 & 261 (26.2) & $10(1.0)$ & 979 (98.4) \\
\hline
\end{tabular}

(C) Journal of Thoracic Disease. All rights reserved. 
Table S2 District-specific characteristics of participants in four Chinese cities in Period 1 and Period 2, showing number and proportions (\%, in the parentheses) for each parameter

\begin{tabular}{|c|c|c|c|c|c|c|c|c|c|c|}
\hline \multirow{2}{*}{ City (Period) } & \multirow{2}{*}{ District } & \multirow{2}{*}{$\mathrm{N}$} & \multicolumn{4}{|c|}{ Male } & \multicolumn{4}{|c|}{ Female } \\
\hline & & & Smoking & Education & Blue collar & White collar & Smoking & Education & Blue collar & White collar \\
\hline \multicolumn{11}{|l|}{ Chongqing } \\
\hline Period 1 & Urban & 1011 & 759 (75.1) & 259 (25.6) & $405(40.1)$ & 380 (37.6) & $24(2.4)$ & $151(14.9)$ & 455 (45.0) & 389 (38.5) \\
\hline \multirow[t]{2}{*}{ Period 2} & Urban & 1599 & 703 (44.0) & $393(55.9)$ & $642(40.2)$ & 702 (43.9) & $16(1.0)$ & $380(23.8)$ & 485 (30.3) & 885 (55.3) \\
\hline & Suburban & 527 & 233 (44.2) & 103 (19.5) & $186(35.3)$ & 247 (46.9) & $6(1.1)$ & $104(19.7)$ & $138(26.3)$ & 327 (62.0) \\
\hline \multicolumn{11}{|l|}{ Wuhan } \\
\hline Period 1 & Urban & 1924 & 1613 (83.8) & 324 (16.8) & 1007 (52.3) & 779 (40.5) & $28(1.5)$ & $140(7.3)$ & $1006(52.3)$ & $804(41.8)$ \\
\hline Period 2 & Suburban & 1167 & $542(46.4)$ & 229 (19.6) & $694(59.5)$ & 379 (32.5) & $3(0.3)$ & $187(9.4)$ & $550(47.1)$ & 433 (37.1) \\
\hline \multicolumn{11}{|l|}{ Lanzhou } \\
\hline \multirow[t]{2}{*}{ Period 1} & Urban & 716 & $541(75.6)$ & $98(13.7)$ & $361(50.4)$ & $323(45.1)$ & $6(0.8)$ & $42(5.9)$ & 344 (48.0) & 307 (42.9) \\
\hline & Suburban & 767 & $627(81.7)$ & $1(0.1)$ & $721(94.0)$ & $36(4.7)$ & $3(0.4)$ & $0(0.0)$ & 740 (96.5) & $16(2.1)$ \\
\hline \multirow[t]{2}{*}{ Period 2} & Urban & 848 & $403(47.5)$ & $461(54.4)$ & $142(16.7)$ & $353(41.6)$ & $2(0.2)$ & $426(50.2)$ & 137 (16.2) & $344(40.6)$ \\
\hline & Suburban & 1218 & $541(44.4)$ & 283 (23.2) & $526(43.2)$ & 283 (23.2) & $5(0.4)$ & 261 (21.4) & 412 (33.8) & 355 (29.1) \\
\hline \multicolumn{11}{|l|}{ Guangzhou } \\
\hline Period 1 & Urban & 920 & 635 (69.0) & 177 (19.2) & $314(34.1)$ & 555 (60.3) & $13(1.4)$ & $112(12.2)$ & 312 (33.9) & 545 (59.2) \\
\hline
\end{tabular}


Table S3 Estimates and 95\% CI (in parentheses) of the change in respiratory disease prevalences associated with $1 \%$ decrease in the prevalence of indoor air pollution surrogates or an interquartile range (IQR) decrease in outdoor air pollutant concentrations, based on sensitivity analysis

\begin{tabular}{|c|c|c|c|c|c|c|c|c|}
\hline \multirow{3}{*}{ Variables } & \multicolumn{4}{|c|}{ Period 1} & \multicolumn{4}{|c|}{ Period 2} \\
\hline & \multicolumn{2}{|c|}{ Male } & \multicolumn{2}{|c|}{ Female } & \multicolumn{2}{|c|}{ Male } & \multicolumn{2}{|c|}{ Female } \\
\hline & Asthma & $\begin{array}{c}\text { Chronic } \\
\text { bronchitis }\end{array}$ & Asthma & $\begin{array}{c}\text { Chronic } \\
\text { bronchitis }\end{array}$ & Asthma & $\begin{array}{c}\text { Chronic } \\
\text { bronchitis }\end{array}$ & Asthma & $\begin{array}{l}\text { Chronic } \\
\text { bronchitis }\end{array}$ \\
\hline \multicolumn{9}{|c|}{ Indoor air pollution surrogates } \\
\hline Active smoke & 0.0075 & 0.2746 & 0.7879 & -0.4000 & 0.0116 & -0.0361 & -0.0460 & -0.0183 \\
\hline Kitchen type & 0.0090 & -0.1528 & 0.0287 & -0.0043 & -0.0043 & $0.0518^{\star \star}$ & -0.0038 & 0.0229 \\
\hline Cooking coal & 0.0014 & 0.1684 & $-0.0186^{\star \star}$ & 0.0182 & -0.0194 & 0.2289 & -0.0706 & 0.1346 \\
\hline Cooking ventilation & -0.0010 & -0.0739 & 0.0091 & -0.0071 & 0.0058 & -0.0484 & -0.0097 & -0.0049 \\
\hline $\mathrm{SO}_{2}$ & 0.0019 & -0.0057 & 0.0025 & -0.0001 & 0.0015 & -0.0633 & 0.0020 & -0.0148 \\
\hline
\end{tabular}

**, $\mathrm{P}<0.05$. The IQRs for $\mathrm{PM}_{2.5}, \mathrm{PM}_{10}$ and $\mathrm{SO}_{2}$ are 34,51 , and $43 \mathrm{mg} / \mathrm{m}^{3}$, respectively 